\title{
SUICÍDIO, DIREITO À SAÚDE MENTAL E POLÍTICAS PÚBLICAS: REALIDADE E PERSPECTIVAS FUTURAS
}

\section{SUICIDE, RIGHT TO MENTAL HEALTH AND PUBLIC POLICIES: REALITY AND FUTURE PERSPECTIVES}

Rodrigo Tonel ${ }^{1}$ Janaína Machado Sturza²

DOI: https://doi.org/10.37767/2591-3476(2020)08

\section{RESUMO:}

A reforma psiquiátrica brasileira, através da anuência do nosso país na Declaração de Caracas de 1990, culminou com o advento da Lei N. ${ }^{0} 10.216$ de abril de 2001, mais conhecida por Lei Antimanicomial e, posteriormente, com a Resolução n. ${ }^{\circ} 3.088$ de 23 de dezembro de 2011, com a instituição da Rede de Atenção Psicossocial - RAPS. Nesta perspectiva da saúde mental, apesar de todos os fatores que circundam a contemporaneidade, apresenta um limite - seja pela morte, seja pelo suicídio. O presente artigo tem por objetivo fomentar a reflexão acerca do fenômeno do suicídio, estabelecendo uma interlocução com o adoecimento da humanidade. Através de um estudo bibliográfico, tendo como método de abordagem o hipotético dedutivo, verificou-se que as políticas públicas de prevenção a este fenômeno devem ser propostas sob o olhar multifatorial e multicausal, alicerçadas em acepções da saúde mental.

\begin{abstract}
The Brazilian psychiatric reform, through the consent of our country in the Caracas Declaration of 1990, has culminated with the advent of the Law No. 10,216 of April 2001, better known as Antimanicomial Law and, later, with the Resolution No. 3,088 of December 23, 2011, with the institution of the Psychosocial Care Network - RAPS. In this perspective of mental health, despite all the factors that surround contemporaneity, it presents a limit either by death, or by suicide. This article aims to foster the reflection on the phenomenon of suicide, establishing a dialogue with the sickening of humanity. Through a bibliographic study, using the deductive hypothetical approach method, it's been demonstrated that public policies for the prevention of this phenomenon should be proposed under the multifactorial and multicausal view, based on mental health meanings.
\end{abstract}

\footnotetext{
1 Pesquisador. Bolsista da Coordenação de Aperfeiçoamento de Pessoal de Nível Superior - CAPES; Mestre pelo Programa de Pós-graduação Mestrado e Doutorado em Direitos Humanos da Universidade Regional do Noroeste do Estado do Rio Grande do Sul - UNIJUÍ. Bacharel em Direito pela UNIJUÍ. Integrante do Grupo de Pesquisa Biopolítica e Direitos Humanos -CNPq. E-mail: tonelr@yahoo.com; ORCID iD: https://orcid.org/0000-0003-2480-7426.

2 Pós doutora em Direito pelo Programa de Pós Graduação em Direito da Universidade do Vale do Rio dos Sinos - UNISINOS. Doutora em Direito pela Escola Internacional de Doutorado em Direito e Economia Tullio Ascarelli, da Universidade de Roma Tre/Itália. Mestre em Direito pela Universidade de Santa Cruz do Sul - UNISC. Especialista em Demandas Sociais e Políticas Públicas também pela UNISC. Graduada em Direito pela UNISC. Professora na Universidade Regional do Noroeste do Estado do Rio Grande do Sul - UNIJUÍ, lecionando na graduação em Direito e no Programa de Pós Graduação em Direito - Mestrado e Doutorado. Integrante do Grupo de Pesquisa Biopolítica e Direitos Humanos (CNPq). E-mail: janasturza@hotmail.com; ORCID iD: http://orcid.org/0000-001-9290-1380.
} 
PALAVRAS-CHAVE: Direitos Humanos; Morte; Políticas Públicas; Saúde Mental; Suicídio.

KEY WORDS: Human Rights; Death; Public Policies; Mental Health; Suicide

\section{Introdução}

Até onde tem-se conhecimento, nossa existência - a existência humana, é limitada, ou seja, não podemos viver eternamente, uma vez que nosso corpo físico está condicionado a viver temporariamente devido a fatores biológicos. Morrer é um processo natural da vida, assim como nascer é um acontecimento natural para iniciar o ciclo de vida de um ser vivo.

Todavia, enquanto um nascimento é muitas vezes celebrado com felicidade, a morte é vista com tristeza e geralmente evitada com todos os esforços. Todo ser vivo está destinado a morrer no final de sua vida. Assim, todos nós nascemos, crescemos e vivemos sabendo que um dia morreremos. É verdade que podemos adiar nossa morte através das tecnologias que temos, através de medicamentos e tratamentos, mas não podemos evitar, eternamente, a morte.

No entanto, a partir deste cenário, eis que podemos enfrentar a possibilidade de acabar com nossas vidas - não mais através da morte por causas naturais ou situações inevitáveis, mas através do suicídio enquanto ato intencional de matar a si mesmo.

Neste contexto, o presente artigo objetiva fomentar a reflexão acerca do fenômeno do suicídio e o crescente aumento de sua ocorrência na sociedade contemporânea, estabelecendo uma interlocução com o adoecimento da humanidade, especialmente na perspectiva do direito à saúde mental. Discute-se, igualmente, a importância de políticas públicas voltadas a sua prevenção e decorrente proteção ao direito humano à saúde e consequentemente à vida.

Atualmente, o fenômeno do suicídio destaca-se nas pautas de debates na ceara da saúde pública e, mais especificamente, da saúde mental, no sentido de identificar as principais causas que levam as pessoas a abreviação de sua existência. De igual modo, os debates seguem na tentativa de se construir um entendimento acerca dos temas que envolvem os limites da existência humana e por consequência o suicídio, tais como a autonomia e liberdade do ser humano em dispor ou não pelo seu corpo físico, ou seja, as discussões relativas ao direito à vida e à morte e a liberdade de escolha e/ou opção voluntária do indivíduo pela morte, frente a intervenção do Estado na vida do indivíduo, mediante o dever de proteger a vida.

Assim, portanto, a discussão envolta ao tema ora proposto encontra sua relevância nos campos do direito à saúde, do biodireito e das políticas públicas, além da contribuição jurídica e social no que diz respeito a construção dos fundamentos e marcos teóricos e normativos - afinal, o suicídio deve ser um tema de analise multidisciplinar, especialmente diante do preocupante aumento das taxas de mortes provindas deste fenômeno.

Desta forma, através do método hipotético dedutivo e da técnica de pesquisa bibliográfica, 
verificou-se como essencial e urgente iniciativas de formulação e implementação de políticas públicas de prevenção a este fenômeno, as quais devem ser propostas sob um olhar multifatorial e multicausal, levando-se em consideração aspectos sociais, políticos, midiáticos, culturais e até mesmo religiosos, e, sobretudo, alicerçadas em acepções do biodireito e do direito à saúde mental, no intento de resguardar a vida e a própria espécie humana.

\section{A inexpugnabilidade da morte: argumentos sobre um evento inadiável}

A morte é, por natureza, um acontecimento inexpugnável. Um evento inadiável. Nossa vida se assemelha a lógica da ampulheta, isto é, da mesma forma que a areia da ampulheta vai escoando vagarosamente até que esteja completamente transpassada para a outra face do artefato, assim também acontece com a vida. Somos condenados a um tempo de vida. Findado este tempo, então, não nos resta mais nada a não ser a morte. Para a maioria das pessoas, a areia da ampulheta da vida escoa naturalmente até o seu fim. Já, para algumas pessoas - e não poucas - a areia da ampulheta da vida escoa mais rápido do que naturalmente escorreria devido a interferência e interesse do indivíduo, ou seja, sua vida acaba antes do que outrora naturalmente acabaria e, aqui, a referência é ao suicídio.

Por uma perspectiva filosófica, a morte não pode ser ruim para a pessoa que morreu, ela é ruim para aqueles que continuam vivos, ou seja, as pessoas que amavam o morto como familiares e amigos. Para estas pessoas a morte representa algo ruim justamente porque impossibilita a continuação ou permanência de um vínculo de interação que outrora dispunham com aquele que no presente momento se encontra morto. ${ }^{3}$

Se partirmos do pressuposto de que todo aquele que está morto já não mais existe, então a morte não pode ser considerada nem ruim e nem boa. Teríamos que mudar a pergunta e indagar: Seria a não existência ruim para aquele que já não existe mais?

Ora, para uma não existência não há que se falar em dor e prazer, tristezas e alegrias, derrotas e vitórias. Esses valores só acontecem para aquele que existe. Então, como a morte e/ou não existência pode ser ruim ou boa? Para Kagan, "[...] o que é ruim em estar morto é que você não consegue mais experimentar e aproveitar as várias coisas boas da vida". ${ }^{4}$

Para Lucretius, o período logo após nossa morte não é o único período que simboliza ou se traduz em uma não existência. Existe um outro período de não existência. Basta refletirmos um pouco e perceberemos que se trata de um período pretérito ao nosso nascimento, ou seja, antes de nosso nascimento não existíamos. Aparentemente, não há nada ruim acerca da eternidade de nossa não existência antes de nosso nascimento. Assim, por este seguimento, se não há nada de errado com a não existência antes de nosso nascimento, analogicamente, não há nada de errado com a não existência após a morte. ${ }^{5}$

Para Kübler-Ross, "a morte é parte integrante da vida, tão natural e previsível quanto nascer. Mas enquanto o nascimento é motivo de celebrações, a morte tornou-se uma

3 KAGAN, Shelly (2012): Death. New Haven and London Yale University Press, New Haven and London.

4 KAGAN, Shelly (2012): Death. New Haven and London Yale University Press, New Haven and London. p. 212. Tradução nossa.

5 LUCRETIUS. On the nature of things. Trad.: Cyril Bailey. Disponível em: http://files.libertyfund.org/files/2242/Lucretius_1496_Bk.pdf, Acesso em: 09 jun. 2019. 
questão temida e indecifrável a ser evitada por todos os meios possíveis em nossa sociedade moderna".6

Contudo, não é bem assim. Tratamos diferentemente e assimetricamente estes dois polos de não existência justamente porque quando morremos deixamos de viver, isto é, perdemos algo que tivemos - nossas vidas, ao passo que, durante o período que antecede nosso nascimento, ainda não tivemos a oportunidade de vivenciar ou experimentar a vida para, então, concluirmos que sua perda é algo ruim.

Já para Szasz , "[...] não há objetivamente "boa morte" ou "morte ruim"; só há morrer - ou viver, considerada "boa" ou "má", de acordo com os valores da pessoa que faz o julgamento". ${ }^{\prime}$

Nesse sentido, então, importante se faz destacar que nesta reflexão sobressalta a ideia e o exercício de liberdade no que diz respeito às vidas e corpos, afinal, morrer ou viver, sob a perspectiva do suicídio, está diretamente relacionado à liberdade de dispor do próprio corpo.

\section{Liberdade de dispor do próprio corpo: viver ou morrer?}

Na definição Durkheimiana, "[...] chama-se suicídio todo o caso de morte que resulta direta ou indiretamente de um ato, positivo ou negativo, realizado pela própria vítima e que ela sabia que produziria esse resultado. ${ }^{8}$

Na sociedade ocidental contemporânea onde a ideia e exercício de liberdade é um fator característico e muito aparente, a maioria das pessoas presumem serem autônomas e soberanas no que diz respeito às suas vidas e corpos. Assim, por exemplo, quando alguém é assassinado, se destaca que esse mesmo alguém foi privado de seu direito à vida. Contudo, quando alguém se suicida, frequentemente se diz que isso se sucedeu em razão de que este indivíduo provavelmente sofria de algum tipo de doença mental. Entrementes, neste último caso, não estaria este indivíduo exercendo seu direito de auto propriedade? Não estaria ele constituído de liberdade para dispor de sua própria vida e de seu corpo, e fazer o que bem entender com sua existência diante daquela premissa?

Muitas pessoas parecem inaptas a entenderem ou aceitar o fato de que algumas pessoas escolhem morrer por seu próprio desejo e vontade, e por seus próprios meios. Para aquelas o suicídio é resultado de distúrbios mentais, ou seja, não se leva em consideração a hipótese de acidente, patriotismo, heroísmo, auto sacrifício, ou até mesmo uma forma de martírio, dentre outras. Com isso, se percebe que tudo fica rotulado a doenças mentais. ${ }^{9}$

De acordo com Szasz, “[...] como qualquer ação humana, o suicídio pode ser considerado bom, ruim ou indiferente; elogiado ou condenado; recomendado ou proibido; ou aceito como aceitamos o clima".10

6 KÜBLER-ROSS, Elisabeth (1975): Death: the final stage of growth. A Spectrum Book, New Jersey. p. 5. Tradução nossa.

7 SZASZ, Thomas (2011): Suicide prohibition: the shame of medicine. Syracuse University Press, New York. p. 6. Tradução nossa.

8 DURKHEIM, Émile (2011): O suicídio: estudo de sociologia. Trad.: Mônica Stahel. 2 ed. Editora WMF Martins Fontes, São Paulo. p. 14. Grifo do autor. 9 SZASZ, Thomas (2011): Suicide prohibition: the shame of medicine. Syracuse University Press, New York.

10 SZASZ, Thomas (2011): Suicide prohibition: the shame of medicine. Syracuse University Press, New York. p. 8. Tradução nossa. 
Para Hillman, "[...] a lei não estabeleceu um tribunal que aceite petições de suicídio, de modo que não há maneira de se optar por morte, a não ser infringindo a lei. O suicida é culpado e não pode jamais provar sua inocência".11 Entretanto, sob este prisma a lei nos obriga a viver, mesmo em desacordo com nossas vontades, e isso revela que nossa liberdade é limitada, ela não é plena.

Obviamente que morrer implica efeitos nos variados ramos do Direito. Atemo-nos ao Direito Penal por um momento. Até 1961, o suicídio sempre foi considerado um crime para a maioria das nações. Sempre fora justificado e comparado com o homicídio, uma espécie de auto homicídio. ${ }^{12}$

Contudo, o suicídio sempre fora considerado um crime injustificável. Isso nos leva a compreensão de que, "[...] pode-se matar outras pessoas de muitas maneiras e sob muitas alegações sem se transgredir a lei; mas não se pode nunca, sob hipótese alguma, matar-se de maneira justificável ou desculpável".13 A exceção, entretanto, se dava somente para aquele indivíduo que sofresse de algum tipo de distúrbio mental, que o incapacitasse de raciocinar e de tomar decisões em sã consciência, justamente porque se demonstrava inapto e incompatível a aceitação e observação de um contrato social firmado essencialmente pela razão. Na sociedade contemporânea, no entanto, poucos países ainda mantém o suicídio e a tentativa como um crime tipificado. ${ }^{14}$

Agora, por quais razões as pessoas se matam? Normalmente, porque a vida está tão ruim que não mais vale a pena ser vivida. $E$, portanto, se já não mais vale a pena ser vivida, parece ser melhor morrer. É certo que, cada pessoa tem suas próprias razões ao optar pela morte.

Pensar no suicídio como uma expressão de liberdade é, sem sombra de dúvida, um argumento que pesa bastante. Contudo, se faz necessário mencionar que grande maioria das pessoas que optam pelo suicídio não o fazem como uma expressão de suas liberdades, mas sim, como uma alternativa frente aos variados problemas que as afligem.

Portanto, para a maioria dos casos de suicídio na contemporaneidade, as pessoas não se matam porque querem gozar de suas liberdades, pelo contrário, elas querem continuar vivendo, mas como não encontram alternativas para seus problemas, optam pelo suicídio. Assim, nas palavras de Hume, “[...] eu acredito que nenhum homem jogou fora a vida enquanto ela ainda valesse a pena ser mantida". ${ }^{15}$

Além disso, frustrações, tristezas e dores também são partes constituintes da vida humana. Só que quando estamos tristes, frustrados ou com dores, nossa capacidade de reflexão é prejudicada consideravelmente. Deste modo, quando optamos pelo suicídio, temos que ter consciência real da decisão que estamos tomando. Se nossa

\footnotetext{
11 HILlMAN, Jamesm (2009): Suicídio e alma. Trad.: Sônia Maria Caiuby Labate. Vozes, Petrópolis, RJ. p. 39.

12 MINOIS, Georges (2018): A história do suicídio: a sociedade acidental diante da morte voluntária. Editora Unesp, São Paulo.

13 HILLMAN, Jamesm (2009): Suicídio e alma. Trad.: Sônia Maria Caiuby Labate. Vozes, Petrópolis, RJ. p. 39.

14 MISHARA, Brian L., WEISSTUB, David N. (2016): “The legal status of suicide: a global review." International Journal of Law and Psychiatry, Volume 44, Page 54-74, doi: https://doi.org/10.1016/j.ijlp.2015.08.032. Disponível em: https://www.sciencedirect.com/science/article/pii/S0160252715001429, Acesso em: 03 jul. 2019

15 HUME, David (1777): On suicide. Penguin Books - Great Ideas, England. p. 10. Tradução nossa.
} 
capacidade de discernimento é confundida pela dor, tristeza ou frustração, então, não temos como saber se o suicídio realmente é a coisa certa a fazer.

Portanto, evidencia-se, nesta conjuntura, que o suicídio é um fenômeno multicausal e multifatorial - em outras palavras, resta claro que o suicídio nem sempre ocorrerá necessariamente por razões patológicas.

\section{0 adoecimento emocional da humanidade}

Nossa sociedade contemporânea é caracterizada pelo progresso quando comparada a períodos pretéritos. De acordo com Pinker (2019, p. 4, tradução nossa), temos “[...] recémnascidos que viverão mais de oito décadas, mercados transbordando de comida, água limpa que aparece com um estalar de dedo e desperdício que desaparece com outro, pílula que apaga uma infecção dolorosa, filhos que não são enviados a guerra, filhas que podem andar pelas ruas em segurança, críticos dos poderosos que não são presos ou fuzilados, conhecimento e cultura do mundo disponíveis no bolso da camisa [...]."16

De acordo com Pinker, portanto, nossa humanidade experimenta um momento no qual nunca em sua história foi registrado um índice tão elevado de progresso, isto é, somos mais felizes, saudáveis, vivemos mais do que nossos antepassados, avançamos para a igualdade de direitos, temos democracia, somos mais informados, estamos mais seguros, não vivemos em um momento marcado por guerras, enfim, nossa condição atual é muito boa. ${ }^{17}$

Contudo, muitos pensadores discordam com essa perspectiva de progresso, afirmando que vivemos em um momento apocalíptico, atribuindo a culpa ao capitalismo tecnológico, o qual tem amaldiçoado as pessoas, tornando-as extremamente individualistas, egocentristas, consumeristas, materialistas, insensíveis, ostentatórias, atomizadas, entre outros tantos adjetivos. Dentre esses autores, poderíamos citar Bauman - que em suas múltiplas obras discorre sobre o conceito de liquidez de nossa sociedade contemporânea, afirmando, a título de ilustração, que trocamos os relacionamentos reais pelos virtuais, rompemos as relações sociais reais pelas virtuais, criando maior isolamento e individualismo entre as pessoas. ${ }^{18}$

Lipovetsky, por sua vez, aponta para uma sociedade de hiperconsumo, que tem como característica principal a busca da felicidade através do consumo de objetos. Consequentemente, esses tipos de compreensões apenas fazem com que as pessoas mergulhem cada vez mais no abismo da solidão. ${ }^{19}$

Outro autor que aponta para o adoecimento emocional da humanidade é o sul-coreano Byung-Chul Han, trazendo a compreensão de uma sociedade que se encontra física e psiquicamente esgotada - Síndrome do Burnout, marcada por uma onda de positividade e perfeccionismo, que leva ao surgimento e a sobreposição de doenças neurológicas sobre os demais tipos de doenças epidêmicas. Isso tudo contribui decisivamente para a

\footnotetext{
16 PINKER, Steven (2019): The enlightenment now: the case for reason, science and humanism. Penguin Random Science, United Kingdom. p. 4, tradução nossa. 17 PINKER, Steven (2019): The enlightenment now: the case for reason, science and humanism. Penguin Random Science, United Kingdom.

18 BAUMAN, Zygmunt (2004): Amor líquido: sobre a fragilidade dos laços humanos. Trad.: Carlos Alberto Medeiros. Jorge Zahar, Rio de Janeiro. Disponível em: http://static.tumblr.com/jh0avtj/8xdooienw/amor_liquido_-_zygmunt_bauman.pdf, Acesso em: 11 ago. 2019.

19 LIPOVETSKY, Gilles (2007): A felicidade paradoxal: ensaio sobre a sociedade do hiperconsumo. Trad.: Maria Lúcia Machado. Companhia das Letras, São Paulo.
} 
intensificação do fenômeno do suicídio em nossa sociedade contemporânea. ${ }^{20}$

Ademais, basta checarmos o site da Organização Mundial da Saúde para observarmos que, atualmente, cerca de quase um milhão de pessoas se suicidam todos os anos. Para sermos mais precisos, o número gira em torno de 800.000 mil óbitos por suicídio por ano, isto é, o mesmo que um suicídio a cada 40 segundos. Ainda assim, existe a indicação de que a cada 1 suicídio consumado, outros 20 foram tentados. O suicídio pode ocorrer em qualquer momento da vida, todavia, encontra-se em segundo lugar no ranking das causas de morte entre jovens de 15 a 29 anos no mundo. ${ }^{21}$ Os números são, inegavelmente, alarmantes. No entanto, a referida fonte sugere que a grande maioria desses suicídios poderiam ser evitados.

No caso brasileiro, entre os anos de 2007 e 2016, foram registrados cerca de "[...] 106.374 óbitos por suicídio. Em 2016, a taxa chegou a 5,8 por 100 mil habitantes, com a notificação de 11.433 mortes por essa causa". 22

No Brasil, observamos uma acentuada diferença com relação ao gênero. De acordo com o Ministério da Saúde, o suicídio é a terceira principal causa de morte entre pessoas do sexo masculino, e a oitava principal causa de morte entre pessoas do sexo feminino. ${ }^{23}$

Além disso, de acordo com Jaen-Varas et al., no Brasil, o fenômeno do suicídio aumentou em $24 \%$ entre os adolescentes brasileiros que residem em grandes cidades, e no geral 13\%, dos anos de 2006 a 2015. As razões principais desse aumento do suicídio no Brasil são as mudanças socioeconômicas dos últimos anos, o excessivo uso da Internet e a falta de políticas públicas de prevenção. A utilização indiscriminada da Internet, principalmente, no que diz respeito a participação e exposição assídua de adolescentes em redes sociais, aumenta a sensação de isolamento e pode estimular os adolescentes ao suicídio. ${ }^{24}$

Esse isolamento e entristecimento da humanidade configura o suicídio Durkheimiano chamado egoísta, porque enfraquece os laços que unem o indivíduo a sua sociedade. Ele representa um afrouxamento da estrutura social, ou seja, a fragilização dos laços grupais que nutrem o corpo social. Ele é responsável pela desintegração social, ferindo as balizas sociais e, consequentemente, desestruturando a sociedade. Assim, tal fenômeno é considerado um inimigo da sociedade e, portanto, sua ocorrência deve ser prevenida e evitada. ${ }^{25}$

A prevenção, então, seria basicamente trazer de volta ao grupo social aquele indivíduo que se afastou. Isso porque o isolamento individual, para fora do grupo social, é a

20 HAN, Byung-Chul (2015): The burnout society. Stanford University Press, Stanford, California.

21 WORLD HEALTH ORGANIZATION (2018): Latest data on suicide. Disponível em: http://www.who.int/mental_health/suicide-prevention/en/, Acesso em: 05 ago. 2019.

22 MINISTÉRIO DA SAÚDE (2018): Novos dados reforçam a importância da prevenção do suicídio. Disponível em: http://portalms.saude.gov.br/noticias/ agencia-saude/44404-novos-dados-reforcam-a-importancia-da-prevencao-do-suicidio, Acesso em: 05 ago. 2019.

23 MINISTÉRIO DA SAÛDE (2017): Secretaria de Vigilância em Saúde. Perfil epidemiológico das tentativas e óbitos por suicídio no Brasil e a rede de atenção à saúde. Volume 48, n³0. Disponível em: http://portalarquivos2.saude.gov.br/images/pdf/2017/setembro/21/2017-025-Perfil-epidemiologico-dastentativas-e-obitos-por-suicidio-no-Brasil-e-a-rede-de-atencao-a-saude.pdf, Acesso em: 05 ago. 2019.

24 JAEN-VARAS, Denisse. et al. (2019): “The association between adolescent suicide rates and socioeconomic indicators in Brazil: a 10-year retrospective ecological study." Brazilian Journal of Psychiatry, doi: http://dx.doi.org/10.1590/1516-4446-2018-0223. Disponível em: http://www.scielo.br/scielo. php?script=sci_arttext\&pid=S1516-44462019005003105\&lng=en\&nrm=iso\#B03, Acesso em: 05 ago. 2019.

25 DURKHEIM, Émile (2011): O suicídio: estudo de sociologia. Trad.: Mônica Stahel. $2^{\circ}$ ed. Editora WMF Martins Fontes, São Paulo. 
determinante que leva o indivíduo a tendência suicida. Deste modo, a prevenção sociológica do suicídio é o fortalecimento grupal. Juntos somos mais fortes, juntos tornamo-nos imunes ao suicídio.

Assim, portanto, a prevenção do suicídio deve ser tratada na coletividade, sem esquecer, entretanto, das ações voltadas a implementação e fortalecimento das políticas públicas de proteção à saúde mental, e, por consequência, à vida.

4 Suicídio, direito à saúde mental e políticas públicas: realidade e perspectivas futuras Sabemos da barbárie que ocorreu na década de 1960, no Centro Hospitalar Psiquiátrico de Barbacena, mais conhecido por Hospital Colônia, resultando na morte de cerca de 60 mil pessoas, além dos abusos incomensuráveis que os pacientes daquele lugar sofreram e, que, mais tarde ganhou o pseudônimo de Holocausto Brasileiro. ${ }^{26}$

A partir daí, a reforma psiquiátrica brasileira, através da anuência do nosso país na Declaração de Caracas de 1990 - documento que serve de marco para as reformas em atenção na saúde mental nas Américas, ${ }^{27}$ que culminou com o advento da Lei N. ${ }^{\circ} 10.216$ de abril de 2001, mais conhecida por Lei Antimanicomial - que dispõe sobre a proteção e preservação aos direitos daqueles indivíduos acometidos por transtornos mentais ${ }^{28}$ e, posteriormente, em ações mais práticas como é o caso da Resolução n. ${ }^{\circ} 3.088$ de 23 de dezembro de 2011, com a instituição da Rede de Atenção Psicossocial - RAPS, vem a dar amparo para os indivíduos que manifestam algum tipo de sofrimento mental, assim como, adicionalmente, para aqueles com necessidades decorrentes do uso de drogas e álcool. ${ }^{29}$

A política Nacional de Saúde Mental, portanto, é uma ação do governo federal em prol daquelas pessoas que sofrem transtornos mentais oriundos de causas diversas, incluindo dependentes de substâncias psicoativas, como são os casos clássicos do uso de drogas e álcool. Fornece a assistência e o acolhimento devidos não só aos doentes, como também aos seus familiares.

Em períodos de crises, essas pessoas poderão ser atendidas e/ou internadas em um dos Centros de Atenção Psicossocial - CAPS, e receber os serviços da Rede de Atenção Psicossocial - RAPS, sendo aquele um dos pontos que compõem esta rede.

Dentro do viés jurídico, recentemente, o governo federal sancionou a Lei $n^{\circ} 13.819$ de 26 de abril de 2019, que cria a Política Nacional de Prevenção da Automutilação e do Suicídio. Essa política tem como principais objetivos a preservação da saúde mental e a prevenção a violência autoprovocada. O Art. $3^{\circ}$, em seus incisos, estabelece claramente todo o rol de objetivos. No entanto, para o contexto deste estudo, destacamos a importância dos incisos IV, VI e VII. ${ }^{30}$

\footnotetext{
26 ARBEX, Daniela (2013): Holocausto Brasileiro. Geração Editorial, São Paulo.

27 DECLARAÇÃO DE CARACAS. (1990): Disponível em: http://www.abrasme.org.br/resources/download/1358516130_ARQUIVO_ DeclaracaodeCaracas.pdf, Acesso em: 07 ago. 2019.

28 BRASIL (2001): Lei N. ${ }^{0} 10.216$ de 6 de abril de 2001. Disponível em: http://www.planalto.gov.br/ccivil_03/leis/leis_2001/110216.htm, Acesso em: 07 ago. 2019. 29 BRASIL. Ministério da Saúde. Gabinete do Ministro (2011): Portaria n 3.088, de 23 de dezembro de 2011. Disponível em: http://bvsms.saude.gov.br/bvs/ saudelegis/gm/2011/prt3088_23_12_2011_rep.html, Acesso em: 07 ago. 2019.

30 BRASIL (2019): Lei no 13.819, de 26 de abril de 2019. Disponível em: http://www.planalto.gov.br/ccivil_03/_ato2019-2022/2019/lei/L13819.htm, Acesso em: 12 ago. 2019.
} 
No inciso IV, é possível vislumbrar a previsão de garantias em relação ao atendimento psicossocial daqueles indivíduos que manifestem sofrimento psíquico, bem como aqueles que demonstram ideação suicida, tentativas e automutilação. ${ }^{31}$

O inciso VI refere-se a ampla informação e conscientização social com o objetivo de sensibilizar a sociedade para a relevância da temática. E, no inciso VII, é possível perceber o esforço para a promoção intersetorial de prevenção ao suicídio, ou seja, “[...] envolvendo entidades de saúde, educação, comunicação, imprensa, polícia, entre outras". 32

A referida lei, também, estabelece notificação compulsória sempre que as instituições se depararem com casos possíveis ou concretos de violência autoprovocada. Deste modo, de acordo com o Art. $6^{\circ}$, inciso I, estabelecimentos de saúde públicos e privados deverão notificar as autoridades sanitárias. Aditivamente, no inciso II do referido artigo, estabelecimentos de ensino públicos e privados deverão comunicar ao conselho tutelar. O $\S 3^{\circ}$ do referido artigo, acrescenta que essa notificação terá caráter sigiloso. ${ }^{33}$

O Art. $4^{\circ}$ preleciona a respeito da manutenção do serviço telefônico fornecido pelo Centro de Valorização da Vida - CVV, qual seja, uma associação civil sem fins lucrativos, fundada em São Paulo no ano de 1973, que “[...] presta serviço voluntário e gratuito de apoio emocional e prevenção do suicídio para todas as pessoas que querem e precisam conversar, sob total sigilo e anonimato". ${ }^{34} \mathrm{O} \S 1^{\circ}$ deste artigo, ainda dispõe, que serão adotadas outras formas de comunicação, levando em consideração os meios mais utilizados pela população na atualidade, ampliando ainda mais o serviço com o objetivo de alcançar mais pessoas que estejam necessitando de ajuda.

Cabe, notoriamente, ressaltar que o direito à saúde é reconhecido pela Declaração Universal dos Direitos Humanos em seu Art. 25, ${ }^{35}$ na Constituição Federal de 1988 em seus Arts. $6^{\circ}$ e 196, sendo que, neste último, "a saúde é direito de todos e dever do Estado, garantido mediante políticas sociais e econômicas que visem à redução do risco de doença e de outros agravos e ao acesso universal e igualitário às ações e serviços para sua promoção, proteção e recuperação". ${ }^{36}$

Neste contexto, a Política Nacional de Prevenção da Automutilação e do Suicídio é, sem sombra de dúvidas, um importante passo rumo à prevenção de mortes por suicídio e promoção da saúde.

\section{Conclusão}

A saúde é um direito de todos e um dever do Estado. Todavia, a saúde não deve ser confundida simplesmente com a ausência de doenças - seu conceito é muito mais

\footnotetext{
31 BRASIL (2019): Lei no 13.819, de 26 de abril de 2019. Disponível em: http://www.planalto.gov.br/ccivil_03/_ato2019-2022/2019/lei/L13819.htm, Acesso em: 12 ago. 2019.

32 BRASIL (2019): Lei no 13.819, de 26 de abril de 2019. Disponível em: http://www.planalto.gov.br/ccivil_03/_ato2019-2022/2019/lei/L13819.htm, Acesso em: 12 ago. 2019 .

33 BRASIL (2019): Lei no 13.819, de 26 de abril de 2019. Disponível em: http://www.planalto.gov.br/ccivil_03/_ato2019-2022/2019/lei/L13819.htm, Acesso em: 12 ago. 2019

34 CVV. (2019): O cvv. Disponível em: https://www.cvv.org.br/o-cvv/, Acesso em: 07 ago. 2019.

35 UNITED NATIONS (1948): Universal declaration of human rights. Disponível em: https://www.un.org/en/universal-declaration-human-rights/, Acesso em: 12 ago. 2019.

36 BRASIL (1988): Constituição da república federativa do Brasil de 1988. Disponível em: http://www.planalto.gov.br/ccivil_03/constituicao/ constituicaocompilado.htm, Acesso em: 12 ago. 2019.
} 
amplo e abrangente, deve ser compreendida como o bem-estar físico, mental e social. Portanto, seguindo este ideário, devemos prevenir o suicídio não somente sob a perspectiva física e mental, através da medicalização e hospitalização do indivíduo suicida, mas também sob a perspectiva social e jurídica, através da formulação e implementação de políticas públicas de saúde mental, capazes de fomentar e indicar determinantes sociais e marcos regulatórios sanitários, que de fato - e não somente de direito, garantam o direito humano à saúde, protegendo a vida e a própria existência humana.

Notadamente, a interpretação equivocada de que todo o suicida é um louco, pecador ou imoral, causa extrema estigmatização e rotulagens, gerando constrangimentos na vida social, familiar e profissional do indivíduo e, essas situações, ainda contribuem na intensificação da intolerância a sua vida. A sociedade, muitas vezes por falta de informação, ao invés de encontrar meios para prevenir e evitar o suicídio, acaba literalmente atuando como instigadora deste - tudo isso, em algumas ocasiões, aliada à falta de conhecimento, sensibilidade e solidariedade. É mister, antes de tudo, reeducar e informar a sociedade.

Ainda assim, diante de todas as dificuldades e desafios, é sempre importante acreditar na mudança, pois quando se amarra alguém - contenção física, através de métodos como o uso da camisa de força, por exemplo, morre com ele(a) sua dignidade. Além disso, para alcançar a qualidade na saúde mental dos indivíduos, é importante que haja acolhimento e amor. Os profissionais de saúde, assim como toda a sociedade, devem ter orelhas de elefantes e olhos de águia para dar atenção e suporte aquelas pessoas que necessitam de ajuda. É necessário e urgente, portanto, discutir o tema do suicídio, abandonando o individualismo e incentivando o espírito de solidariedade e cooperação humana.

Portanto, o suicídio, enquanto um fenômeno compreendido como ato intencional de matar a si mesmo, deve ser analisado por uma gama muito ampla de fatores e causas, e sua prevenção, do mesmo modo, há que ser proposta de maneira multifatorial e multicausal. Podemos, assim, prevenir os suicídios através de políticas públicas centralizadas na saúde, no biodireito e na educação, que se voltem a promover cidadania e não intolerância. Nas escolas, trabalhar a valorização da vida. Na mídia, campanhas de esclarecimento. Na saúde, maior capacitação, treinamento e preparo aos profissionais. Na legislação, restringir o acesso a meios letais. São essenciais as iniciativas que comunguem políticas públicas e envolvimento da sociedade, com esforços, práticas e ações governamentais ou não governamentais, que incorporem formas múltiplas de prevenção, como são os casos dos RAPS, dos CAPS, do CVV, das campanhas Setembro Amarelo e Janeiro Branco - tudo no intento de combater o adoecimento da humanidade e, por consequência, combater a abreviação da existência humana através do suicídio. 


\section{REFERÊNCIAS BIBLIOGRÁFICAS}

- ARBEX, Daniela (2013): Holocausto Brasileiro. Geração Editorial, São Paulo.

- BAUMAN, Zygmunt (2004): Amor líquido: sobre a fragilidade dos laços humanos. Trad.: Carlos Alberto Medeiros. Jorge Zahar, Rio de Janeiro. Disponível em: http://static.tumblr. com/jh0avtj/8xdooienw/amor_liquido_-_zygmunt_bauman.pdf, Acesso em: 11 ago. 2019. - BRASIL (2019): Lei n 13.819, de 26 de abril de 2019. Disponível em: http://www.planalto. gov.br/ccivil_03/_ato2019-2022/2019/lei/L13819.htm, Acesso em: 12 ago. 2019.

- BRASIL. Ministério da Saúde. Gabinete do Ministro (2011): Portaria n 3.088, de 23 de dezembro de 2011. Disponível em: http://bvsms.saude.gov.br/bvs/saudelegis/gm/2011/ prt3088_23_12_2011_rep.html, Acesso em: 07 ago. 2019.

- BRASIL (2001): Lei N. ${ }^{\circ} 10.216$ de 6 de abril de 2001. Disponível em: http://www.planalto. gov.br/ccivil_03/leis/leis_2001/l10216.htm, Acesso em: 07 ago. 2019.

- BRASIL (1988): Constituição da república federativa do Brasil de 1988. Disponível em: http://www.planalto.gov.br/ccivil_03/constituicao/constituicaocompilado.htm, Acesso em: 12 ago. 2019.

- CVV. (2019): O cvv. Disponível em: https://www.cvv.org.br/o-cvv/, Acesso em: 07 ago. 2019.

- DECLARAÇÃO DE CARACAS. (1990): Disponível em: http://www.abrasme.org.br/resources/download/1358516130_ARQUIVO_DeclaracaodeCaracas.pdf, Acesso em: 07 ago. 2019. - DURKHEIM, Émile (2011): O suicídio: estudo de sociologia. Trad.: Mônica Stahel. $2^{\circ}$ ed. Editora WMF Martins Fontes, São Paulo.

- HAN, Byung-Chul (2015): The burnout society. Stanford University Press, Stanford, California.

- HILLMAN, Jamesm (2009): Suicídio e alma. Trad.: Sônia Maria Caiuby Labate. Vozes, Petrópolis, RJ.

- HUME, David (1777): On suicide. Penguin Books - Great Ideas, England.

- JAEN-VARAS, Denisse. et al. (2019): "The association between adolescent suicide rates and socioeconomic indicators in Brazil: a 10-year retrospective ecological study." Brazilian Journal of Psychiatry, doi: http://dx.doi.org/10.1590/1516-4446-2018-0223. Disponível em: http://www.scielo.br/scielo.php?script=sci_arttext\&pid=S1516-44462019005003105\&Ing =en\&nrm=iso\#B03, Acesso em: 05 ago. 2019.

- KAGAN, Shelly (2012): Death. New Haven and London Yale University Press, New Haven and London.

- KÜBLER-ROSS, Elisabeth (1975): Death: the final stage of growth. A Spectrum Book, New Jersey. - LIPOVETSKY, Gilles (2007): A felicidade paradoxal: ensaio sobre a sociedade do hiperconsumo. Trad.: Maria Lúcia Machado. Companhia das Letras, São Paulo.

- LUCRETIUS. On the nature of things. Trad.: Cyril Bailey. Disponível em: http://files.libertyfund.org/files/2242/Lucretius_1496_Bk.pdf, Acesso em: 09 jun. 2019.

- MINISTÉRIO DA SAÚDE (2018): Novos dados reforçam a importância da prevenção do suicídio. Disponível em: http://portalms.saude.gov.br/noticias/agencia-saude/44404-novos-dados-reforcam-a-importancia-da-prevencao-do-suicidio, Acesso em: 05 ago. 2019.

- MINISTÉRIO DA SAÚDE (2017): Secretaria de Vigilância em Saúde. Perfil epidemiológico das tentativas e óbitos por suicídio no Brasil e a rede de atenção à saúde. Volume 48, n³0. Disponível em: http://portalarquivos2.saude.gov.br/images/pdf/2017/ setembro/21/2017-025-Perfil-epidemiologico-das-tentativas-e-obitos-por-suicidio-noBrasil-e-a-rede-de-atencao-a-saude.pdf, Acesso em: 05 ago. 2019.

- MINOIS, Georges (2018): A história do suicídio: a sociedade acidental diante da morte voluntária. Editora Unesp, São Paulo.

- MISHARA, Brian L., WEISSTUB, David N. (2016): "The legal status of suicide: a global review." International Journal of Law and Psychiatry, Volume 44, Page 54-74, doi: https:// 
doi.org/10.1016/j.ijlp.2015.08.032. Disponível em: https://www.sciencedirect.com/science/article/pii/S0160252715001429, Acesso em: 03 jul. 2019.

- PINKER, Steven (2019): The enlightenment now: the case for reason, science and humanism. Penguin Random Science, United Kingdom.

- SZASZ, Thomas (2011): Suicide prohibition: the shame of medicine. Syracuse University Press, New York.

- UNITED NATIONS (1948): Universal declaration of human rights. Disponível em: https:// www.un.org/en/universal-declaration-human-rights/, Acesso em: 12 ago. 2019.

-WORLD HEALTH ORGANIZATION (2018): Latest data on suicide. Disponível em: http:// www.who.int/mental_health/suicide-prevention/en/, Acesso em: 05 ago. 2019. 